\title{
Commentary: Teaching an old dog a new trick
}

\author{
Jack S. Shanewise, MD, FASE
}

\footnotetext{
From the Division of Cardiothoracic Anesthesiology, Vagelos College of Physicians \& Surgeons at Columbia University, New York, NY.

Disclosures: Author has nothing to disclose with regard to commercial support.

Received for publication Sept 27, 2019; revisions received Sept 27, 2019; accepted for publication Sept 27, 2019; available ahead of print Oct 8, 2019.

Address for reprints: Jack S. Shanewise, MD, FASE, Division of Cardiothoracic Anesthesiology, Vagelos College of Physicians \& Surgeons at Columbia University, 622 W 168th St, PH5-505, New York, NY 10032 (E-mail: jss2128@columbia.edu).

J Thorac Cardiovasc Surg 2020;160:720-1

$0022-5223 / \$ 36.00$

Copyright $(2019$ by The American Association for Thoracic Surgery

https://doi.org/10.1016/j.jtcvs.2019.09.132
}

I cannot think of another old-fashioned medicine more critical to current practice than aspirin. Willow bark, which is loaded with salicylates, was known to the ancient Egyptians and prescribed by Hippocrates as an analgesic and antipyretic. First synthetized in 1856 by Charles Frédéric Gerhardt and by the end of the nineteenth century produced in bulk by Bayer to sell worldwide, acetylsalicylic acid (also known as ASA) is the prototypic blockbuster drug. Bayer's brand name-Aspirin-was so commonplace that it officially became the generic name in much of the world. Even the doses many of us still use are old-fashioned: $325 \mathrm{mg}$ is 5 grains, and $81 \mathrm{mg}$ is $1 \frac{1}{4}$ grains. Then, in the mid-20th century, as aspirin's role in treating pain and fever was being supplanted by other, less-toxic nonsteroidal antiinflammatory drugs and acetaminophen (INN paracetamol), a new use was discovered, important to this day. We all exist between the rock and the hard place of too much clotting and too much bleeding. Aspirin's effect on platelet function modulates this delicate balance favorably for many patients with cardiovascular disease, decreasing the incidence of heart attacks and strokes, and, for some, even death.

In their article in this issue of the Journal, Aboul-Hassan and colleagues ${ }^{1}$ suggest yet another possible benefit of aspirin: renal protection during coronary artery bypass grafting surgery (CABG); not a new claim, ${ }^{2}$ but one not consistently validated by previously published trials. ${ }^{3}$ Their observational study may shed some light on the reason why. They looked at postoperative renal function in patients undergoing CABG who were taking aspirin for at least a week before surgery, comparing those who took their last dose of aspirin less than 24 hours before surgery with those whose last dose was between 24 and 48 hours. The under 24 hour group had less acute kidney injury after surgery, suggesting that the timing of the last preoperative dose matters. They found no difference in bleeding or transfusion. The association was even stronger in a propensity-matched subgroup. This is important, because acute kidney injury after CABG is common and, even when mild, associated with decreased

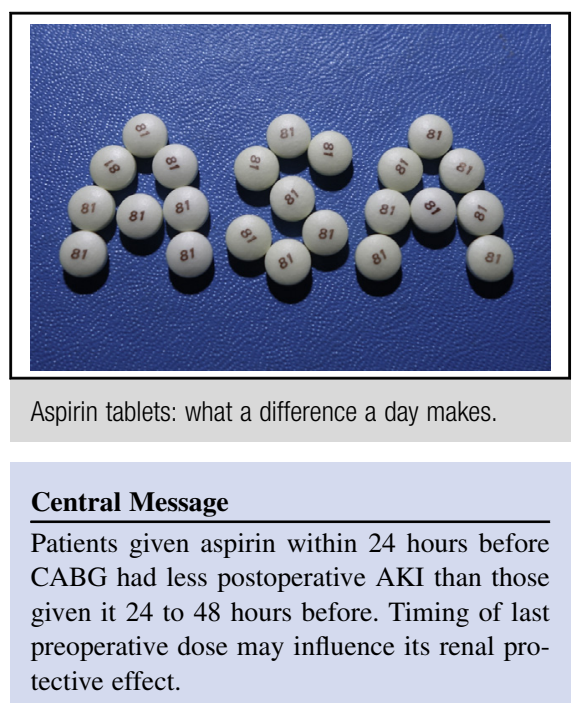

See Article page 712

long-term survival. ${ }^{4}$ Because aspirin irreversibly inhibits the enzyme cyclooxygenase-1, and platelets lack nuclei to make more, the antiplatelet effect of a single dose of aspirin lasts until the affected platelets are replaced, which takes 5 to 7 days. Cells with nuclei, however, such as renal endothelium and epithelium, can replace the blocked enzyme in a few hours, possibly negating some of aspirin's beneficial effects after just 1 day.

Aspirin's myriad, complex effects on inflammation and coagulation continue to be the subject of intense investigation, and this intriguing report suggests that the renal protective property posited for it deserves more attention as well. Meanwhile, maybe all those patients undergoing CABG who are taking aspirin before surgery, as now recommended by at least 1 guideline, ${ }^{5}$ should be sure to take a dose the day of surgery-along with their $\beta$-blocker! This should not change the bleeding risk, but it may help preserve renal function and, hopefully, long-term survival.

\section{References}

1. Aboul-Hassan SS, Marczak J, Stankowski T, Peksa M, Nawotka M, Stanislawski R, et al. Association between preoperative aspirin and acute kidney injury following coronary artery bypass grafting. J Thorac Cardiovasc Surg. 2020; 160:712-9.

2. Mangano DT; Multicenter Study of Perioperative Ischemia Research Group. Aspirin and mortality from coronary bypass surgery. N Engl J Med. 2002;347: 1309-17.

3. Myles PS, Smith JA, Forbes A, Silbert B, Jayarajah M, Painter T, et al; ATACAS Investigators of the ANZCA Clinical Trials Network. Stopping vs. continuing aspirin before coronary artery surgery. N Engl J Med. 2016;374:728-37. 
4. Bouma HR, Mungroop HE, de Geus AF, Huisman DD, Nijsten MWN, Mariani MA, et al. Acute kidney injury classification underestimates long-term mortality after cardiac valve operations. Ann Thorac Surg. 2018;106:92-8.
5. Sousa-Uva M, Head SJ, Milojevic M, Collet JP, Landoni G, Castella M, et al. 2017 EACTS guidelines on perioperative medication in adult cardiac surgery. Eur $J$ Cardiothorac Surg. 2018;53:5-33. 